\title{
PEDOT Modified Carbon Paste Microelectrodes for Scanning Electrochemical Microscopy ${ }^{\dagger}$
}

\author{
Balazs Csoka $^{a, *}$ and Zineb Mekhalif ${ }^{b}$ \\ ${ }^{a}$ Department of Analytical and Environmental Chemistry, Faculty of Sciences, University of Pécs, \\ Ifjúság útja 6, H-7624 Pécs, Hungary \\ ${ }^{\mathrm{b}}$ Laboratory of Chemistry and Electrochemistry of Surfaces, University of Namur (FUNDP), \\ Rue de Bruxelles 61, B-5000 Namur, Belgium
}

\begin{abstract}
Only one measuring tip was used in three different modes of operation of the Scanning Electrochemical Microscope (feed-back mode, generation-collection mode, potentiometry) to collect chemical information about copper targets. The tip was formed from 5 and $25 \mu \mathrm{m}$ diameter conventional platinum microdisk electrode by etching a cavity, then electrochemically depositing poly(3,4-ethylenedioxythiophene) (PEDOT) layer doped with hexacyanoferrate and finally filling with modified carbon paste based $\mathrm{Cu}^{2+}$ sensing layer. The preparation and electrochemical working parameters of this kind of solidcontact microelectrodes are discussed as well as SECM applications for copper detection is reported. (doi: $10.5562 /$ cca1784)
\end{abstract}

Keywords: carbon paste, PEDOT, SECM, potentiometry, amperometry

\section{INTRODUCTION}

Ion-selective electrodes are widely used tools for direct determination of ionic species in low activity. ${ }^{1,2}$ Important trends in ion-selective electrode development lead to lowering the detection limits ${ }^{3,4}$ miniaturizing $^{5-7}$ and constructing solid state setups. ${ }^{8-10}$ Conducting polymers are popular in solid state potentiometric electrode design. ${ }^{1-16}$ The reason for the popularity is the high stability, low resistivity and the easy way of reproducible preparation. The role of the conducting polymers is the ion-to-electron signal transduction between the sensing layer and the metal contact. ${ }^{17}$ By varying the doping anions of the positively charged polymer backbone, the functions of the polymer can be tailored according to the needs. ${ }^{18}$ In our recent work, hexacyano-ferrate (II) anion was used as counter ion of the poly(3,4-ethylenedioxythiophene) (PEDOT) backbone to form a proper layer between the carbon paste based sensing element and the platinum wire.

Carbon paste (CP) is an often used material for electrode preparation. ${ }^{19-22}$ The easy way of preparation, simple renewal, low material costs are causing the high interest about it. Using different modifiers it can be used for creating selective sensing materials for either amperometric $^{20}$ or potentiometric methods. ${ }^{21,22}$ The use of carbon paste with incorporated ionophore can be advantageous also in microelectrode design, as compared to the metal wire microelectrodes for ion-selective measurements (electrodes of the first kind). Carbon paste surface will not be passivated, however, metal wire electrode surfaces can take part in reactions with ions of the electrolyte.

Scanning Electrochemical Microscopy (SECM) allows collecting local chemical information or doing modifications on materials with micro- or even nanometer resolution. ${ }^{23-25}$ By scanning over the surfaces using different modes of operations, various information can be reached about the chemical properties of the area checked. In order to do this, special electrochemical microsensors should be prepared and used. There were only a few publications about microelectrodes capable to use in both amperometric and potentiometric modes of operation. Denuault et al. published results with $\mathrm{Ag}^{+}$ ion-selective $\mathrm{Ag} \mid \mathrm{AgCl}$ tips, ${ }^{26}$ or antimony and gallium microelectrodes can be used as $\mathrm{H}^{+}$sensitive tips, ${ }^{27,28}$ while both electrodes are also capable to measure feedback current.

Recessed microdisk electrode was fabricated and used for potentiometric as well as amperometric applications of the Scanning Electrochemical Microscope in our previous publication. ${ }^{29}$ The big advantage of the

\footnotetext{
$\uparrow$ Presented at the $10^{\text {th }}$ International Symposium and Summer School on Bioanalysis within the CEEPUS Network CII-HU-001004-0910, Zagreb, Croatia, July 2010.

* Author to whom correspondence should be addressed. (E-mail: csoki@ttk.pte.hu)
} 
new type electrode is the capability of using it in both modes of SECM operations: in potentiometry it acts as $\mathrm{Cu}^{2+}$ ion-selective microsensor while in amperometry it was used in feed-back mode to set the tip-to-target distance. In order to enhance the analytical performance, especially in potentiometric mode, the electrode design was modified by incorporating a conducting polymer layer. According to our knowledge, preparation of electrodes using PEDOT layer and carbon paste has not been reported.

In this paper we describe first, the experimental results regarding the elaboration of the electrode, comparing results obtained by the previously published nonPEDOT containing ones, then the application of this PEDOT modified carbon paste microdisk electrode for SECM measurements. Experimental results are presented in terms of successful scanning in all three modes of SECM operation.

\section{EXPERIMENTAL}

\section{Materials}

All the chemicals used were obtained from SigmaAldrich. A $25 \mu \mathrm{m}$ diameter Pt wire was obtained from Goodfellow, UK. Polishing was done with 5, 1 and 0.03 $\mu \mathrm{m}$ particle size $\mathrm{Al}_{2} \mathrm{O}_{3}$ polishing powder obtained from Bühler (Lake Bluff, USA).

MilliQ water was used to prepare solutions with $18.2 \mathrm{M} \Omega \mathrm{cm}^{-1}$ specific resistivity. To keep the ionic strength constant $0.1 \mathrm{M} \mathrm{KNO}_{3}$ solution was used as a standard background solution with $\mathrm{pH}=4.0$ set by diluted $\mathrm{HNO}_{3}$.

\section{Electrode Preparation}

The electrode preparation process is based on the method already published for carbon paste filled platinum microelectrodes. ${ }^{29}$ Only a short outline is given here. The electrode fabrication process was begun with the construction of standard Pt disk microelectrodes on the usual way: 5 and $25 \mu \mathrm{m} \mathrm{Pt}$ wires were incorporated into the soft glass capillaries, and then by polishing them to have a conventional metal-glass microelectrode tip with a metal-to-glass ratio $1: 10$ in diameter. The correct operation of the microelectrodes was tested by running cyclic voltammetries in $1 \mathrm{mM}$ ferrocenemethanol (FC$\mathrm{MeOH}$ ) in $0.1 \mathrm{M} \mathrm{KNO}_{3}$ solution.

Before recession, the $\mathrm{Pt}$ surface was cleaned in $1 \mathrm{M} \mathrm{H}_{2} \mathrm{SO}_{4}$ solution by running $\mathrm{CVs}$ from -2 to $+2 \mathrm{~V}$ with a speed of $200 \mathrm{mV} \mathrm{s}^{-1}$ for reaching a steady-state current response. The $\mathrm{Pt}$ metal was etched from the electrode body electrochemically by applying $5 \mathrm{~V}, 50 \mathrm{~Hz}$ AC voltage to the electrode. The composition of the solution used for etching was slightly modified as published earlier by increasing the $\mathrm{HCl}$ amount: $v\left(\mathrm{CaCl}_{2}\right.$, sat. $): v\left(\mathrm{H}_{2} \mathrm{O}\right): v(\mathrm{HCl}$, conc. $)=60: 30: 10$. The
Pt wires, especially the $5 \mu \mathrm{m}$ i.d., showed better dissolution in the modified solution. After recession the prepared cavity was cleaned by ultrasonicating in acetone for $15 \mathrm{~min}$ and drying under $\mathrm{N}_{2}$ flux.

After cleaning, the cavity was observed under optical microscope and the platinum surface often seemed unequally etched, resulting in irregular metal surface. In order to produce a more flat surface before filling with carbon paste, the platinum surface was covered by an electronically conducting polymer layer. Our aim was to reduce the possibility of the air bubble inclusion into the deeper parts of the surface during the carbon paste filling, but not influencing the beneficial high electric conductivity of the electrode. The PEDOT layer has been prepared in order to cover and align these irregularities.

The PEDOT layer was deposited onto the platinum surface in depth of the cavity from aqueous solution of $0.01 \mathrm{M}$ 3,4-ethylenedioxythiophene (EDOT) and $0.02 \mathrm{M} \mathrm{K}_{4}\left[\mathrm{Fe}(\mathrm{CN})_{6}\right]$. The solution containing EDOT monomer and hexacyanoferrate (HCF) was deoxygenated by $\mathrm{N}_{2}$ for $30 \mathrm{~min}$ before use. The polymerization was carried out by running CVs between -0.2 and $1.1 \mathrm{~V}$ with $50 \mathrm{mV} \mathrm{s}^{-1}$ scan rate. After 10 cycles the electrode was removed from the polymerization cell, it was rinsed with water and was checked under optical microscope.

From the total charge recorded during polymerization the estimated PEDOT/HCF layer thickness was calculated according the data published by Bobacka et $a l .^{30}$ and it was found to be between 0.5 and $1.0 \mu \mathrm{m}$. An electrochemical verification was also done in $1 \mathrm{M} \mathrm{KCl}$ by running CVs between -0.5 and $0.5 \mathrm{~V}$ with $20 \mathrm{mV} \mathrm{s}^{-1}$ scan rate. After testing, the PEDOT containing tip was immersed in acetone for seconds and dried under $\mathrm{N}_{2}$ to eliminate the water content on the PEDOT - sensing layer interface in order to get more stable potentiometric signal. $^{31}$

The sensing layer was prepared from tetraethylthiuram-disulfide containing carbon paste with paraffin oil carrier as it was already published. ${ }^{29}$ Thiuram containing paste $(w=10 \%)$ was selected to use as sensing material (CP10), and it was top filled into the cavity, directly on the PEDOT/HFC layer. As the last step, the carbon paste filled microelectrode $(\mu \mathrm{CP})$ was tested electrochemically by running CVs in $1 \mathrm{mM}$ ferrocenemethanol solution. The voltamogram obtained was compared with CVs taken using conventional 5 and 25 $\mu \mathrm{m}$ Pt disk microelectrodes.

\section{Targets for SECM Measurements}

Copper plate was polished with $\mathrm{Al}_{2} \mathrm{O}_{3}$ powder series having $5,1,0.03 \mu \mathrm{m}$ particle size. The surface was thoroughly rinsed with distilled water after polishing. The final, mirror-like surface was partly covered by plastic scotch-tape, in the middle part leaving about 150 $\mu \mathrm{m}$ thin, linear area uncovered. 
In other experiments conventional copper grid for transmission electron microscopy (TEM) was used as target without any further modification. It was a 300 mesh copper grid having $17 \mu \mathrm{m}$ bar width and $70 \mu \mathrm{m}$ hole width. The grid was carefully glued onto a glass slide before fixing horizontally into the bottom of the SECM cell.

\section{Instrumentation}

The SECM measurements were carried out with a CHI900B (CH Instruments, Austin, TX) Scanning Electrochemical Microscope. For potentiometric measurements a home-built battery powered voltage follower was connected between the microelectrode and the potentiostat unit of the CHI900B.

Three-electrode setup was used for amperometry with Pt wire counter electrode and $\mathrm{Ag}|\mathrm{AgCl}| 3 \mathrm{M} \mathrm{KCl}$ reference electrode, while two electrodes (reference + sensing) were used for potentiometry. The targets were held at open circuit potential during all the measurements.

\section{RESULTS AND DISCUSSION}

\section{Calibration}

For potentiometry the electrodes were calibrated in $\mathrm{CuSO}_{4}$ solutions within the activity range between $1 \times 10^{-8}$ and $1 \times 10^{-2} \mathrm{~mol} \mathrm{dm}^{-3}$. The electromotive force was measured in each solution. The emf values measured for $25 \mu \mathrm{m}$ diameter electrodes were plotted against activity considering the extended Debye-Hückel equation as shown in Figure 1. The slope of the calibration plot of an unconditioned electrode is strongly superNernstian in the whole range, with the slope of 112 $\mathrm{mV} /$ decade, and a lower detection limit of $3 \times 10^{-6} \mathrm{M}$. This is a similar observation to our recently published one, ${ }^{29}$ which was measured by using carbon paste based microelectrodes without PEDOT contact. The supposed reason for the high slope is the adsorption of the metal ions on the surface of carbon paste material. Similar super-Nernstian responses induced by copper were observed also for other ions in conventional membranes, however, the reason for the super-Nernstian behavior has not been found. ${ }^{32}$

The influence of the electrode polarization to the calibration data was also necessary to check. In order to set the electrode's distance from the target, an approach need to be made using the amperometric feed-back mode, by keeping the electrode potential at a constant value, and recording the current as a function of distance. It is obvious to use the reduction current of the dissolved oxygen to take the approach, thus no further compounds are necessary to use. At $-0.6 \mathrm{~V}(v s . \mathrm{Ag} \mid \mathrm{AgCl})$ the oxygen reduction can be measured easily, however

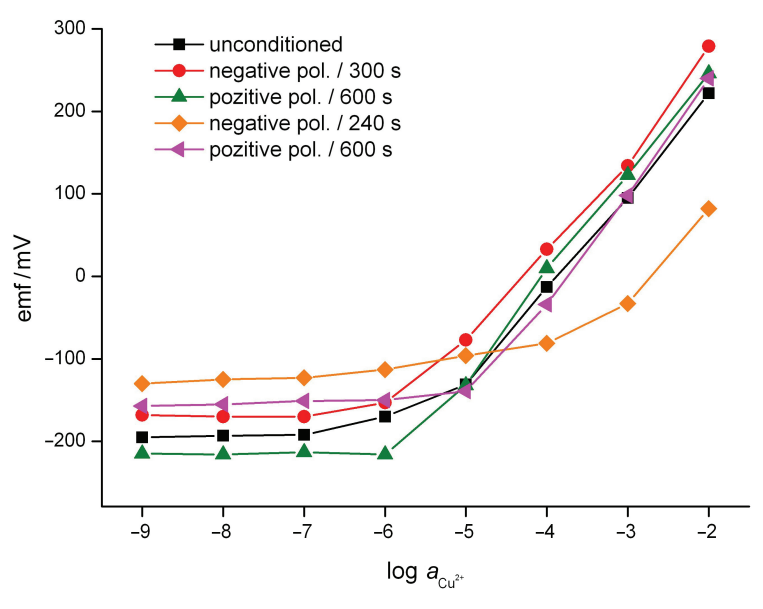

Figure 1. Calibration plot for differently treated $25 \mu \mathrm{m}$ diameter PEDOT modified CP electrodes: unconditioned electrode, Limit of Detection $=3.0 \times 10^{-6} \mathrm{M}(\boldsymbol{\square})$; polarization in $10^{-5} \mathrm{M}$ $\mathrm{Cu}^{2+}$ solution at $-600 \mathrm{mV}$ for $300 \mathrm{~s}, \mathrm{LOD}=1.82 \times 10^{-6} \mathrm{M}(\bullet)$; polarization in $10^{-5} \mathrm{M} \mathrm{Cu}^{2+}$ solution at $+600 \mathrm{mV}$ for $600 \mathrm{~s}$, LOD $=1.26 \times 10^{-6} \mathrm{M}(\Delta)$; polarization in $10^{-2} \mathrm{M} \mathrm{Cu}^{2+}$ solution at $-600 \mathrm{mV}$ for $240 \mathrm{~s}, \mathrm{LOD}=1.74 \times 10^{-4} \mathrm{M}(\diamond)$; polarization in $10^{-9} \mathrm{M} \mathrm{Cu}^{2+}$ solution at $+600 \mathrm{mV}$ for $600 \mathrm{~s}$, LOD $=$ $7.94 \times 10^{-6} \mathrm{M}(<)$.

by polarizing the electrode negatively it is forcing the HCF ions to leave the polymer layer ${ }^{18,31,33}$ and copper ions are collected at the outer surface of the carbon paste causing decreased sensitivity, as it had been already published. ${ }^{29}$ The diffusion of $\mathrm{HCF}$, however, towards the solution is hindered by the CP. During a forthcoming positive polarization the HCF can be reoxidized and forced to diffuse back to the PEDOT matrix.

The calibration plots obtained after negative and forthcoming positive polarization are presented in Figure 1 . The curves show a change in sensitivity towards the primary ions comparing it to an unconditioned electrode ( $\boldsymbol{\square})$. In the first test the electrode was polarized to $-600 \mathrm{mV}$ for $5 \mathrm{~min}$ in $1 \times 10^{-5} \mathrm{M} \mathrm{Cu}^{2+}$ solution $(\bullet)$. The curve shows slightly higher emf values, and better limit of detection: $\log a$ changed from -5.52 to -5.74 . In a forthcoming positive polarization to $+600 \mathrm{mV}$ for $10 \mathrm{~min}$ in $1 \times 10^{-5} \mathrm{M}$ solution the values are closer to original ones, however, a significantly lower detection limit was reached: $\log a_{\mathrm{Cu}^{2+}}=-5.90 \mathrm{M}(\mathbf{\Delta})$. To test the effect of negative polarization $(-600 \mathrm{mV})$ in much higher copper concentration $1 \times 10^{-2} \mathrm{M}$ solution was used for $5 \mathrm{~min}$. The values obtained show a very limited response, comparing to any previous curve $(\diamond)$. By applying a positive potential $(+600 \mathrm{mV})$ in a low concentration solution $\left(1 \times 10^{-9} \mathrm{M}\right)$ the emf values are almost reaching the values measured for unconditioned electrode (४).

Because of the hydrophobicity of the paraffin oil carrier, there is no evidence of water accumulation beneath the carbon paste layer. We suppose that only a small 


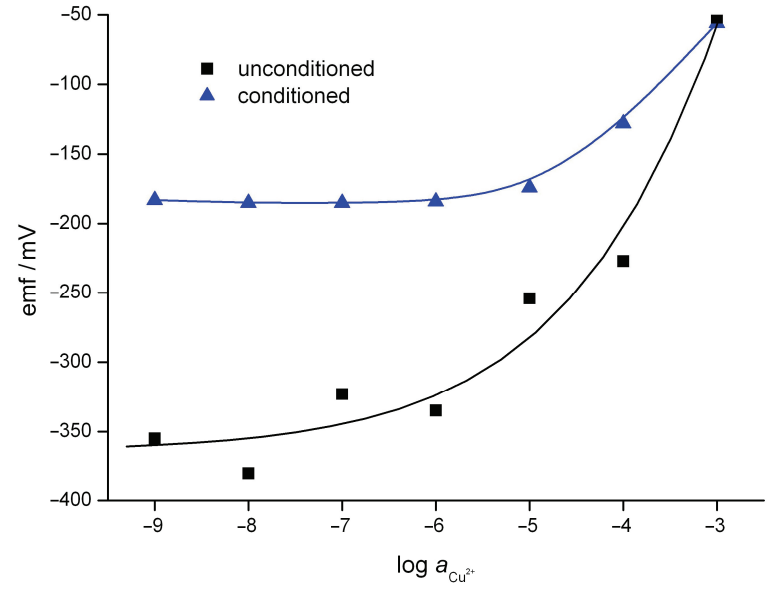

Figure 2. Calibration plot of $5 \mu \mathrm{m}$ i.d. PEDOT modified CP electrodes: unconditioned electrode $(\boldsymbol{\square})$; conditioned in $10^{-6} \mathrm{M} \mathrm{Cu}^{2+}$ solution overnight $(\mathbf{A})$.

amount of the copper from the sample will penetrate into the CP layer during the negative polarization, and it will be fully stripped out by the forthcoming positive polarization. By comparing the calibration curves on Figure 1, the benefits of the positive polarization over the negatively polarized electrodes is shown, as already described above.

These tests proved that the effect of negative polarization is not influencing seriously the sensitivity of the electrode for potentiometric measurements, as: $(i)$ the concentration of copper ions in solution is low and (ii), a forthcoming positive polarization is also done. One can conclude that the SECM approaching in amperometric mode does not reduce the potentiometric sensitivity of the microelectrode, as a positive polarization is also applied.

The calibration plot for $5 \mu \mathrm{m}$ PEDOT modified $\mathrm{CP}$ electrodes are shown in Figure 2.

Unfortunately the values were not stable for the new electrodes. (घ) Different methods were tried for improving the analytical parameters. The best results were obtained by conditioning the microelectrodes overnight in $1 \times 10^{-6} \mathrm{M} \mathrm{Cu}^{2+}$ solution. (A) As a negative effect this method has led to a prolonged response time $\left(\tau_{\mathrm{R}}>300 \mathrm{sec}\right)$, thus $5 \mu \mathrm{m}$ electrodes were not used in further experiments.

\section{Selectivity}

The selectivity coefficient of the new electrodes was checked towards some common metal ions. The measurements were carried out according to the Matched Potential Method, due to the strong super-Nernstian response of the microelectrodes towards the $\mathrm{Cu}^{2+}$ ions. ${ }^{34}$ The results did not show significant deviation from the values already published about microelectrodes without polymer layer. ${ }^{29}$ This can be understood as one thinks about the same composition of the sensing layer.
Because of the same reason, taking care of the $\mathrm{pH}$ dependence and the influence of the ionic strength to the measurements, $0.1 \mathrm{M} \mathrm{KNO}_{3}$ solution with a $\mathrm{pH}=4.0$ was used throughout for potentiometric measurements.

\section{Stability, Response Time}

The response time of the microelectrodes was a critical point considering the SECM potentoimetric measurements, a long response time can elongate the SECM scanning to inacceptable length. The $\tau_{90}$ values were obtained as the emf values reached the $90 \%$ of the stabilized one. Response time into forward direction, as the solution was changed from $1 \times 10^{-4} \mathrm{M}$ to $1 \times 10^{-3} \mathrm{M}$ in case of the unconditioned electrodes was $34 \mathrm{~s}$, while into backward direction (changing the solution from $1 \times 10^{-3} \mathrm{M}$ to $1 \times 10^{-4} \mathrm{M}$ ) it was $82 \mathrm{~s}$. Comparing this values with the ones previously published (without PEDOT prepared electrodes filled with CP containing $10 \%$ thiuram), we can see that the response of the novel electrodes became slower.

The potentiometric stability was checked in standard solution. Unfortunately the stability values of the PEDOT modified electrodes were worse than the previous electrodes, in this case $8-12 \mathrm{mV}$ potential changes were recorded within 60 minutes. The reason can be possibly found in the improper elimination of the water layer from the PEDOT/CP interface. The other reason of the water layer formation can be the copper-HCF complex, as copper ions may penetrate the $\mathrm{CP}$ layer within longer time of use. The copper-HCF has low solubility and as a deposit at the interface would indeed increase the probability of water accumulation.

However, electrodes with these parameters were also suitable for SECM imaging.

\section{SECM Measurements}

\section{Scanning Over Copper Plate}

The copper target was fixed into the cell, and tip-totarget distance was set to $11 \mu \mathrm{m}$ by amperometric approach in $0.1 \mathrm{M} \mathrm{KNO}_{3}$ solution, using the dissolved oxygen as mediator. All the scanning was performed over a $1500 \times 300 \mu \mathrm{m}$ area by keeping this constant distance. The distance from the surface was set by amperometric approach, continued with a positive polarization. $25 \mu \mathrm{m}$ step distance was applied between each measurement point during the scan, while the scanning speed was $2,10,25 \mu \mathrm{m} \mathrm{s}^{-1}$ in potentiometric mode, in generation-collection mode and in feed-back mode, respectively.

The first run in potentimetric mode was performed. $25 \mu \mathrm{m}$ diameter $\mathrm{CP}$ modified microelectrode served as ion-selective microsensor and $\mathrm{Ag} \mid \mathrm{AgCl}$ reference electrode closed the measuring circuit. For potenti 

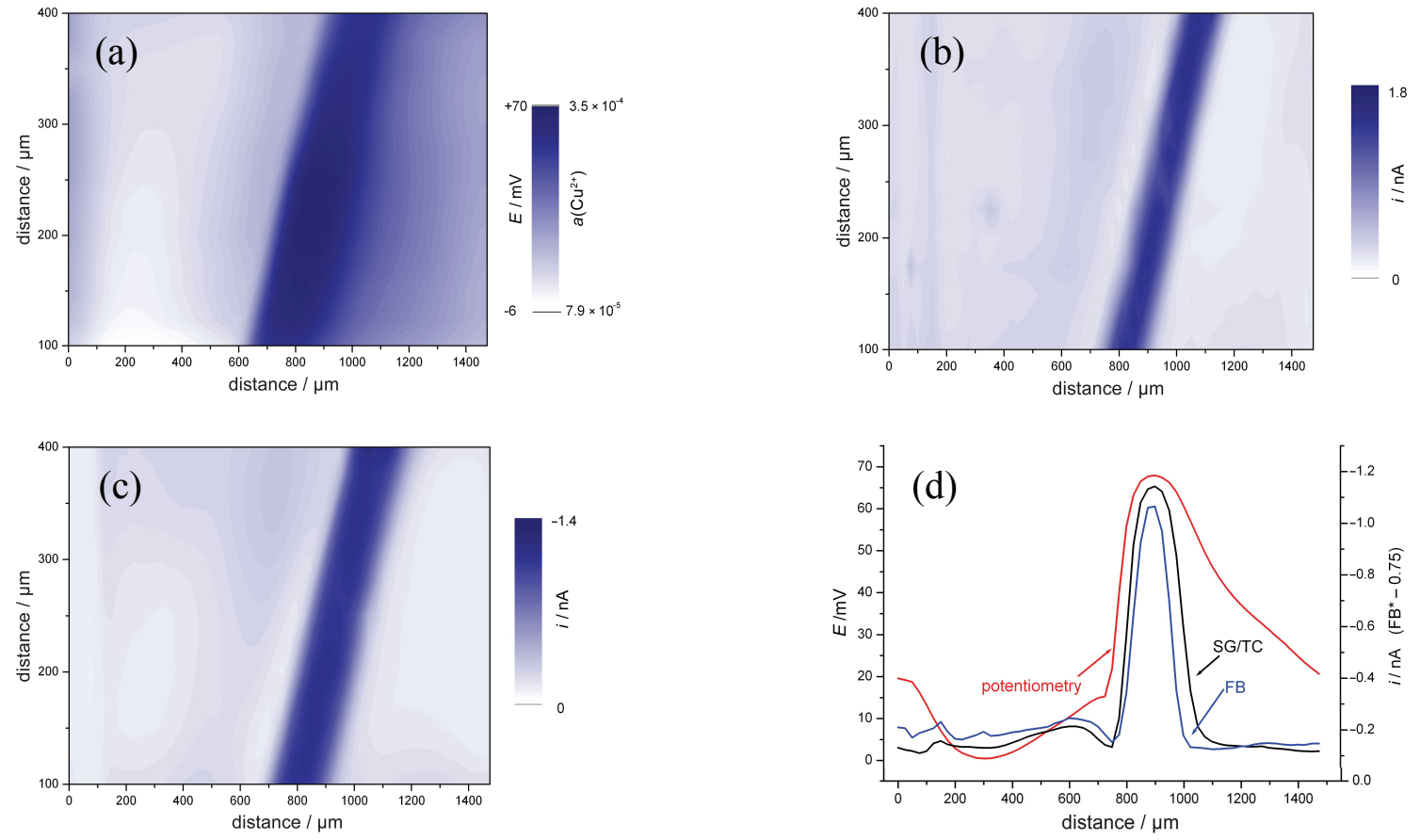

Figure 3. Scanning the same area over a partly covered copper plate with different methods: potentiometry in $0.1 \mathrm{M} \mathrm{KNO}_{3}$ solution (a); feed-back mode in $1 \mathrm{mM} \mathrm{FC}-\mathrm{MeOH}+0.1 \mathrm{M} \mathrm{KNO}_{3}$ solution. $E_{\text {tip }}=+0.4 \mathrm{~V} \mathrm{(b)}$; substrate generation, tip collection mode in $0.1 \mathrm{M} \mathrm{KNO}_{3}, E_{\text {tip }}=-0.3 \mathrm{~V}$ (c); Cross section at $\mathrm{Y}=200 \mu \mathrm{m}$ (Please note, that the FB measured values were multiplied by -0.75 and shown on the right axis) (d).

ometric measurements $0.1 \mathrm{M} \mathrm{KNO}_{3}$ background electrolyte was used. To create the image the collected emf data was plotted against the coordinates. After scanning over the target the electrode was moved again into the starting position and amperometric "target generation tip collection" (GC) mode was used to detect the dissolved $\mathrm{Cu}^{2+}$ ions over the same region as in potentiometric mode. Classical three electrode setup was used in the same solution as already used during potentiometric measurements. Now, the working electrode was polarized to $-0.6 \mathrm{~V}$, where the $\mathrm{Cu}^{2+}$ ions in the solution can be reduced.

As the scan in amperometric GC mode was finished, the electrode was repositioned again to the starting coordinates, and the area was scanned again in feedback (FB) mode. In order to do this, the concentration of the solution was changed to $c$ (ferrocenemethanol) $=$ $1 \mathrm{mmol} \mathrm{dm}^{-3}$ in $0.1 \mathrm{M} \mathrm{KNO}_{3}$, and $+0.4 \mathrm{~V}$ potential was applied to the tip, where the $\mathrm{FC}-\mathrm{MeOH}$ oxidation current can be measured.

\section{Scanning Over Copper Grid}

Experiments on the copper grid target were performed on the same way as on the previously mentioned target, except, that the amperometric GC mode experiments were not performed. $400 \times 200 \mu \mathrm{m}$ area was scanned in this case, and $12 \mu \mathrm{m}$ step distance was used; all the other parameters were kept unchanged.

\section{SECM Results}

Images obtained by scanning over the copper line can be seen in Figure 3. The location of the non-covered area is dark blue colored on all the images, and is easy to identify. The signal measured in FB mode is the oxidation current of the FC-MeOH and the SECM "feedback" effect over the conducting (copper) surface. (Figure $3 \mathrm{c}$ ) Because of the short tip-to-target distance (approximately $11 \mu \mathrm{m}$ ) the oxidation current is higher, as the tip's position is over the metal area (positive feedback), and lower as the tip is above the plastic covered area (negative feed-back effect ${ }^{25}$ ). In amperometric GC mode the tip monitors the local variation of the dissolved copper by reducing it to $\mathrm{Cu}^{0}$ form. However, in potentiometric mode the tip is passive; it gives emf response according to concentration distribution of the dissolved copper without taking part in any chemical reaction. Thus, in these experiments the FB mode image shows the conducting property of the target, while the $\mathrm{GC}$ and potentiometric results are corresponding to the locally dissolved copper ions.

Sharp borders of the copper line were found in FB and GC mode, while in potentimetry, the especially as the tip moved from copper to plastic, the borders are much softer. It is also shown in Figure 3d, where a line scan was drawn. This effect is caused by the differences in the response time of the microsensor using in three 

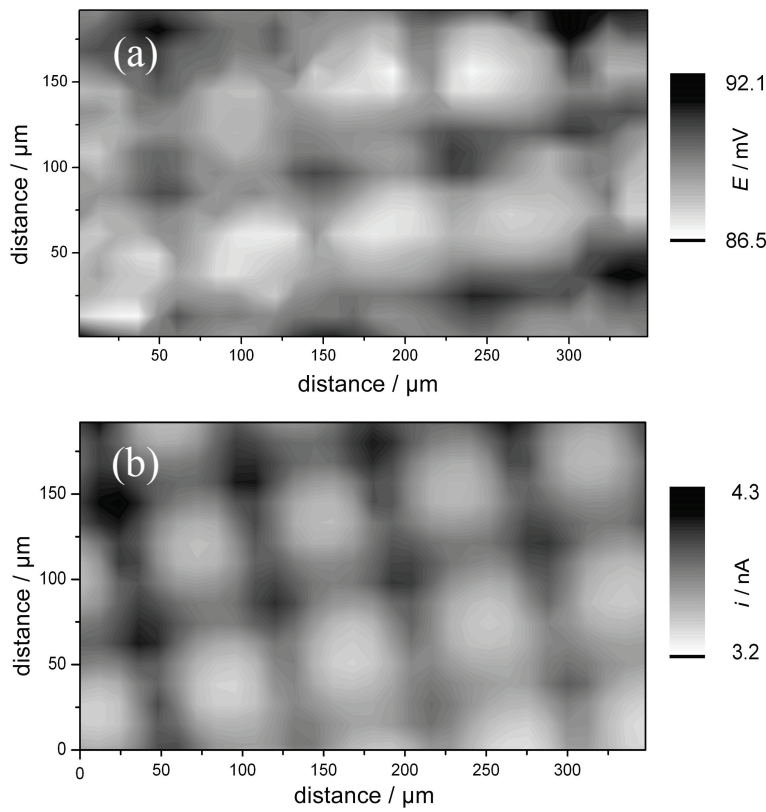

Figure 4. SECM images of a 300 mesh TEM copper grid: potentiometry in $0.1 \mathrm{M} \mathrm{KNO}_{3}$ solution (a); feed-back mode in $1 \mathrm{mM} \mathrm{FC}-\mathrm{MeOH}+0.1 \mathrm{M} \mathrm{KNO}_{3}$ solution. $E_{\text {tip }}=+0.4 \mathrm{~V}(\mathrm{~b})$.

modes of operation. The amperometric response (FB and $\mathrm{GC}$ mode) of the microelectrode is much faster than the potentiometric one, especially in backward direction.

As the copper grid was chosen for target the copper bars are much thinner (about only $1 / 10$ as in previously experiment), thus the copper dissolution and the emf signal will be also lower. This is the reason while in potentiometric mode the image is much more smashed than in FB mode. The images can be found in Figure 4.

These SECM image results prove that it is possible to measure with a specially designed $\mathrm{Cu}^{2+}$ ionselective tip in potentiometric and also in amperometric modes (in FB as well as in GC modes).

\section{CONCLUSIONS}

Scanning Electrochemical Microscopic images were taken over two different copper targets. The low resistivity of novel type PEDOT modified carbon paste electrode makes it possible in one hand to perform the measurements in amperometric modes, while on the other hand the $\mathrm{Cu}^{2+}$ ion-selective property of the thiuram content of the carbon paste allows potentiometric imaging. The results introduced are promising for the further development of the modified carbon paste based electrodes to detect other compounds.

Acknowledgements. Financial support of this work for B. Cs. by the FUNDP-CERUNA fellowship is gratefully acknowledged and the CEEPUS Network (HU-0010) financing is highly appreciated. Z. M. thanks the FRS-FNRS for the SECM equipment.

\section{REFERENCES}

1. P. Buhlmann, E. Pretsch, and E. Bakker, Chem. Rev. 98 (1998) 1593-1687.

2. E. Bakker and E.Pretsch, Angew. Chem. Int. Ed. 46 (2007) 5660 5668 .

3. T. Sokalski, A. Ceresa, T. Zwickl, and E. Pretsch, J. Am. Chem. Soc. 119 (1997) 11347-11348.

4. E. Lindner, R. E. Gyurcsányi, and R. P. Buck, Electroanal. 11 (1999) 695-702.

5. A. Uhlig, F. Dietrich, E. Lindner, U. Schnakenberg, and R. Hintsche, Sens. Actuators, B. 34 (1996) 252-257.

6. E. Pretsch and E. Bakker, Trends Anal. Chem. 27 (2008) 612 618.

7. G. Jágerszki, Á. Takács, I. Bitter, and R. E. Gyurcsányi, Angew. Chem. Int. Ed. 50 (2011) 1656-1659.

8. R. E. Gyurcsányi, A. S. Nyback, K. Tóth, G. Nagy, and A. Ivaska, Analyst 123 (1998) 1339-1344.

9. R. E. Gyurcsányi, N. Rangisetty, S. Clifton, B. D. Pendley, and E. Lindner, Talanta 63 (2004) 89-99.

10. E. Bakker, P. Buhlmann, and E. Pretsch, Electroanal. 11 (1999) 915-933.

11. P. Sjoberg-Eerola, J. Nylund, J. Bobacka, A. Lewenstam, and A. Ivaska, Sens. Actuators, B. 134 (2008) 878-886.

12. J. Bobacka, A. Ivaska, and A. Lewenstam, Chem. Rev. 108 (2008) 329-351.

13. F. Faridbod, M. R. Ganjali, R. Dinarvand, and P. Norouzi, Sensors 8 (2008) 2331-2412.

14. M. Vazquez, J. Bobacka, A. Ivaska, and A. Lewenstam, Sens. Actuators, B. 82 (2002) 7-13.

15. A. Cadogan, Z. Gao, A. Lewenstam, and A. Ivaska, Anal. Chem. 64 (1992) 2496-2501.

16. J. Bobacka, Electroanalysis 18 (2006) 7-18.

17. P. Sjöberg-Eerola, J. Bobacka, A. Lewenstam, and A. Ivaska, Sens. Actuators, B. 127 (2007) 545-553.

18. M. Ocypa, A. Michalska, and K. Maksymiuk, Electrochim. Acta 51 (2006) 2298-2305.

19. R. N. Adams, Anal. Chem. 30 (1958) 1576.

20. E. Bakker and Y. Qin, Anal. Chem. 78 (2006) 3965-3983.

21. A. Abbaspour, M. Asadi, A. Ghaffarinejad, and E. Safaei, Talanta 66 (2005) 931-936.

22. I. Svancara, P. Foret, and K. Vytras, Talanta 64 (2004) 844-852.

23. A. J. Bard, F.-R. F. Fan, J. Kwak, and O. Lev, Anal. Chem. 61 (1989) 132-138.

24. A. J. Bard, G. Denault, R. A. Friesner, B. C. Dornblaser, and L. S. Tuckerman, Anal. Chem. 63 (1991) 1282-1288.

25. G. Wittstock, Appl. Phys. 85 (2003) 335-364.

26. G. Denuault, M. H. Troise Frank, and L. M. Peter, Faraday Discuss. 94 (1992) 23-35.

27. B. R. Horrocks, M. V. Mirkin, D. T. Pierce, A. J. Bard, G. Nagy, and K. Toth, Anal. Chem. 65 (1993) 1213-1224.

28. C. Wei, A. J. Bard, I. Kapui, G. Nagy, and K. Toth, Anal. Chem. 68 (1996) 2651-2655.

29. B. Csoka and Z. Mekhalif, Electrochim. Acta 54 (2009) 32253232 .

30. J. Bobacka, A. Lewenstam, and A. Ivaska, J. Electroanal. Chem. 489 (2000) 17-27.

31. F. Sundfors, R. Bereczki, J. Bobacka, K. Toth, A. Ivaska, and R. E. Gyurcsanyi, Electroanal. 18 (2006) 1372-1378.

32. J. Szűcs, E. Pretsch, and R. E. Gyurcsányi Analyst 134 (2009) 1601-1607.

33. A. Michalska, A. Gałuszkiewicz, M. Ogonowska, M. Ocypa, and K. Maksymiuk, J. Solid State Eletrochem. 8 (2004) 381-389.

34. Y. Umezawa, Ph. Buhlmann, K. Umezawa, K. Tohda, and S. Amemiya, Pure Appl. Chem. 72 (2000) 1851. 